This item was submitted to Loughborough's Research Repository by the author.

Items in Figshare are protected by copyright, with all rights reserved, unless otherwise indicated.

\title{
A computational study of mechanical performance of bioresorbable polymeric stents with design variations
}

PLEASE CITE THE PUBLISHED VERSION

https://doi.org/10.1007/s13239-018-00397-9

\section{PUBLISHER}

(C) Biomedical Engineering Society. Published by Springer Verlag

\section{VERSION}

AM (Accepted Manuscript)

\section{PUBLISHER STATEMENT}

This is a post-peer-review, pre-copyedit version of an article published in Cardiovascular Engineering and Technology. The final authenticated version is available online at: https://doi.org/10.1007/s13239-018-00397-9

\section{LICENCE}

CC BY-NC-ND 4.0

\section{REPOSITORY RECORD}

Qiu, Tianyang, Liguo Zhao, and Mo Song. 2018. "A Computational Study of Mechanical Performance of Bioresorbable Polymeric Stents with Design Variations”. figshare. https://hdl.handle.net/2134/36290. 


\title{
A Computational Study of Mechanical Performance of Bioresorbable Polymeric
}

\section{Stents with Design Variations}

\author{
TY Qiu ${ }^{\mathrm{a}^{*}}$, LG Zhao ${ }^{\mathrm{b}, \mathrm{c}}$ and M Song ${ }^{\mathrm{d}}$ \\ ${ }^{a}$ Key Laboratory of Fundamental Science for Advanced Macbining \\ Beijing Institute of Technology, Beijing, China \\ ${ }^{b}$ Wolfson School of Mechanical, Electrical and Manufacturing Engineering \\ Loughborough University, LE11 3TU, Leicestershire, UK \\ 'School of Mechanical and Equipment Engineering, Hebei University of Engineering, \\ Handan 056038, Cbina \\ ${ }^{d}$ Department of Materials \\ Loughborough University, LE11 3TU, Leicestershire, UK \\ *Corresponding author: E-mail: qiutianyangustu@126.com
}

\begin{abstract}
Purpose: The study compared the mechanical behavior of bioresorbable polymeric stents with various designs during deployment, and investigated their fatigue performance under pulsatile blood pressure loading. Methods: Finite element simulations have been carried out to compare the mechanical performance of four bioresorbable polymeric stents, i.e., Absorb, Elixir, Igaki-Tamai and RevaMedical, during deployment in diseased artery. Tri-folded balloon was modelled to expand the crimped stent onto the three-layered arterial wall with plaque. Cyclic diastolic-systolic pressure loading was applied to both stent and arterial wall to study fatigue behavior. Results: Stents with larger U-bend and longer axial strut demonstrate more flexibility but suffer from severe dogboning and recoiling effects. Stress concentrations in the stent, as well as in the plaque and artery, are higher for stents designed with increased rigidity such as
\end{abstract}


those with smaller U-bends and shorter axial struts. Simulations of fatigue deformation for Elixir stent demonstrate that the U-bends, with high stress concentrations, have a potential risk of fatigue failure under pulsatile systolic-diastolic blood pressure as opposed to the counter metallic stents which are normally free of fatigue failure.

Conclusion: The structural behaviour of bioresorbable polymeric stent is strongly affected by its design, in terms of expansion, dogboing, recoiling and stress distribution during the deployment process.

Keywords: Bioresorbable polymeric stents; Stent expansion; Recoiling and dogboning, Fatigue life; Finite element.

\section{Introduction}

Stenting is a standard clinical procedure to treat blocked arteries and restore normal flow of blood. Bioresorbable polymeric stents have attracted considerable interests recently, because they can provide lumen support for an appropriate period of times and then disappear, leading to a reduction of clinical complications (e.g. thrombosis, in-stent restenosis and inflammation) typically caused by metallic stents ${ }^{1}$. Bioresorbable polymeric stents are mostly made of Poly-l-lactic acid (PLLA), which can break down to natural by-products (i.e., water, CO2, N2, biomass and inorganic salts) after biodegradation. Experimentally, there is a challenge to study mechanical properties of stents due to their tiny sizes and complex geometries, and therefore finite element method has been largely used to simulate the deformation of stents, including bioresorbable polymeric stents 
although still limited. For instance, Pauck and Reddy ${ }^{2}$ conducted a computational analysis to investigate the radial strength, recoiling and radial stiffness of PLLA coronary artery stent. Their results revealed that material modulus was an important parameter in determining the mechanics of polymeric stent, and stent design (e.g., strut angle, thickness and width) also affected the mechanical behavior of PLLA stent. Debusschere et al. ${ }^{3}$ used implicit finite element solver to model free expansion of polymer stent and investigated how the balloon-inflation rate affected the mechanical integrity of stent by considering viscoplastic behavior of stent material. Results showed that direct balloon-inflation approach produced lower stresses on stent during expansion. Bobel et al. ${ }^{4}$ conducted bench test (i.e. radial crimping, bending and longitudinal compression) on three PLLA stents with different geometries to investigate their short-term mechanical performance, i.e., the radial strength, flexibility and longitudinal resistance, which were comparable to metallic stents. Recently, Bobel and Mchugh ${ }^{5}$ performed computational modelling for PLLA stent deployment to evaluate recoiling behavior and material fracture as a function of shape memory effect and stent deployment rate, and their results showed that the combined deployment method produced the best performance. Schiavone et al. ${ }^{6}$ compared the mechanical behavior of metallic stent (Xience) and polymeric stent (Absorb) during crimping and deployment in diseased artery using finite element method. The Absorb stent exhibited a lower expansion rate and higher recoiling/dog-boning effect than Xience, due to the difference in stent design and material property, but induced significantly less stresses to plaque and arterial wall. However, a comparative study of polymeric stents with different designs is not available 
according to our literature review.

Commercially, due to the low market share and high cost, the Absorb bioresorbable vascular scaffolds (BVS) were withdrawn from the global market in Sept 2017. Besides, a series of independent clinical trials have been completed to study the long-term outcomes for Absorb BVS, such as ABSORB China trial, ABSORB Japan trial and ABSORB Extend trial. Based on short-term (1 year) outcome, the Absorb BVS showed comparable clinical outcomes to metallic stents, which demonstrated the safety and efficacy of BVS in the treatment of coronary artery disease $\mathrm{s}^{7,8}$. However, disadvantages were found for the Absorb BVS in the long-term clinical outcomes (three years and beyond). For instance, $\mathrm{Xu}$ et al. $^{9}$ reported the three-year clinical outcome of the ABSORB China trial and found an increase in target lesion failure (by $0.3 \%$ ) and stent thrombosis (by $0.9 \%$ ) for Absorb BVS when compared to metallic Xience stent. This long-term deficiency was also reported at the Transcatheter Cardiovascular Therapeutics 2018 conference, 21-25 September 2018, San Diego, California, United States of America $^{10,11}$. The exact cause of the clinical problems has not been confirmed yet, but stent material and design are believed to play key roles in the long-term clinical performance for the Absorb BVS, including the process of degradation and integrity $\operatorname{loss}^{12}$.

In addition, stent fracture has been recognized and frequently reported in clinical studies. Initially, the occurrence of stent fractures was reported in only $1 \%-2 \%$ of patients 
implanted with drug-eluting stents ${ }^{13}$. Recent studies showed higher incidence of stent fracture with the significantly increased number of stent implantations. For instance, Shaikh et al. ${ }^{14}$ addressed that there was $18.6 \%$ of stent fracture observed in 188 patients implanted with drug-eluting stents over 12 -month follow-up. Nakazawa et al. ${ }^{15}$ reported $29 \%$ incidence of stent fracture in 177 human lesions treated with drug-eluting stents over 630 days. The cause of stent fracture is referred to dynamic biomechanical loads (i.e., tension, compression, bending and torsion), corrosive environment, stent materials and varied designs ${ }^{16}$. In particular, fatigue failure, caused by pulsatile blood pressure, plays an important role in the initiation of fracture in stent. Arterial wall is subjected to approximately 70 times systolic-diastolic pulse in one minute, equivalent to $\sim 40$ million times in one year, as a result of heart beating.

The bioresorbable PLLA stents are designed for a lifetime of two years, over which the polymer is absorbed by the human body via 3-stage hydrolytic degradation process. During the initial stage, the polymer undertakes water via gradual diffusion, which leads to slight reduction of molecular weight but without a loss in mass and mechanical strength. At the second stage, a significant reduction of molecular weight is observed due to the hydration of polymer, while the change of mechanical strength is still limited. At the third stage, both mechanical strength and mass reduce significantly because of scission of the amorphous tie chains ${ }^{17,}{ }^{18}$. Therefore, stent properties experience significant change only in the 3rd stage, which is generally towards the end of their lifetime ( 2 years). It is well known that the stented-artery is subjected to approximately 70 
systolic-diastolic pulses in one minute ( $\sim 40$ million cycles in one year) due to heart beating. Therefore, it is important to study the fatigue failure of bioresorbable polymeric stents during their life time.

Computational approaches have been used to assess fatigue behaviour of metallic stents. Li et al. ${ }^{19}$ simulated L605 Co-Cr stent deformation under fatigue loading and evaluated the fatigue life based on Goodman's rule. Their results showed that dangerous points were located at the U-bends of the ring struts. Azaouzi et al. ${ }^{20}$ carried out fatigue life prediction of $316 \mathrm{~L}$ stainless steel stent by means of two approaches, i.e., the well-known Goodman's diagram and the theory of critical distance. They simulated stent deployment in blood vessel, and addressed that stent failure might happen during either the initial deployment of stent or the long period of pulsatile loading after stent deployment. Recently, Dordoni et al. ${ }^{21}$ introduced a principal strain-based criterion for fatigue assessment of nitinol stent, with calibration against fatigue experiments. Results showed that the most stressed zones were located at the link area and the V-strut directly connected to the link area. However, almost all existing work focused on metallic stents, such as Co-Cr, stainless steel and nitinol stents, and there is a lack of study on the fatigue behavior of polymeric stents.

In this paper, deployment of four bioresorbable polymeric stents, i.e., Absorb, Elixir, Igaki-Tamai and RevaMedical stents, in stenotic artery was simulated using finite element method. This study aimed to compare the mechanical performance of four stents with 
different designs during the deployment process. In particular, stress distribution on stents, change of stent diameter against pressure and stent recoiling/dogboning effects were characterized and compared. Furthermore, fatigue failure of polymeric stent was also investigated, which is the first time according to our best knowledge in this area.

\section{Methodology}

\subsection{FE models for stent and stenotic artery}

Four different bioresorbable polymeric stents were considered in this paper, namely, Absorb (Abbott Vascular), Elixir (Elixir Medical), Igaki-Tamai (Kyoto Medical) and RevaMedical (REVA Medical) stents. Geometrical models of the four stents, in fully expanded shape, were created using Abaqus 6.14 CAE (see Figure 1). Generally, stent geometry is defined by three parameters, i.e., axial strut (bridge strut), U-bend strut amplitude and U-bend strut radius, as shown in Figure 2. In this research, Absorb, Elixir and RevaMedical stents, have the same radius and amplitude for the U-bend struts, while the Igaki-Tamai has larger amplitude and smaller radius for U-bend struts. The connective axial strut spacing is also similar for Absorb, Elixir and RevaMedical stents, while the Igaki-Tamai stent has larger axial strut spacing. The geometries and strut thickness of these four stents were taken from various open resources, as summarized in Table 1. The outer diameter and the length of the stents were chosen to be $3 \mathrm{~mm}$ (in expanded shape) and $12 \mathrm{~mm}$, respectively. These stent models were meshed using 3D 8-node hexahedral elements with reduced integration (C3D8R). The mesh density $5 \times 4$ (5 layers through width direction and 4 layers through thickness direction) was used, 
because mesh sensitivity study was undertaken to confirm that convergence was achieved for the stent with mesh density $4 \times 4$.

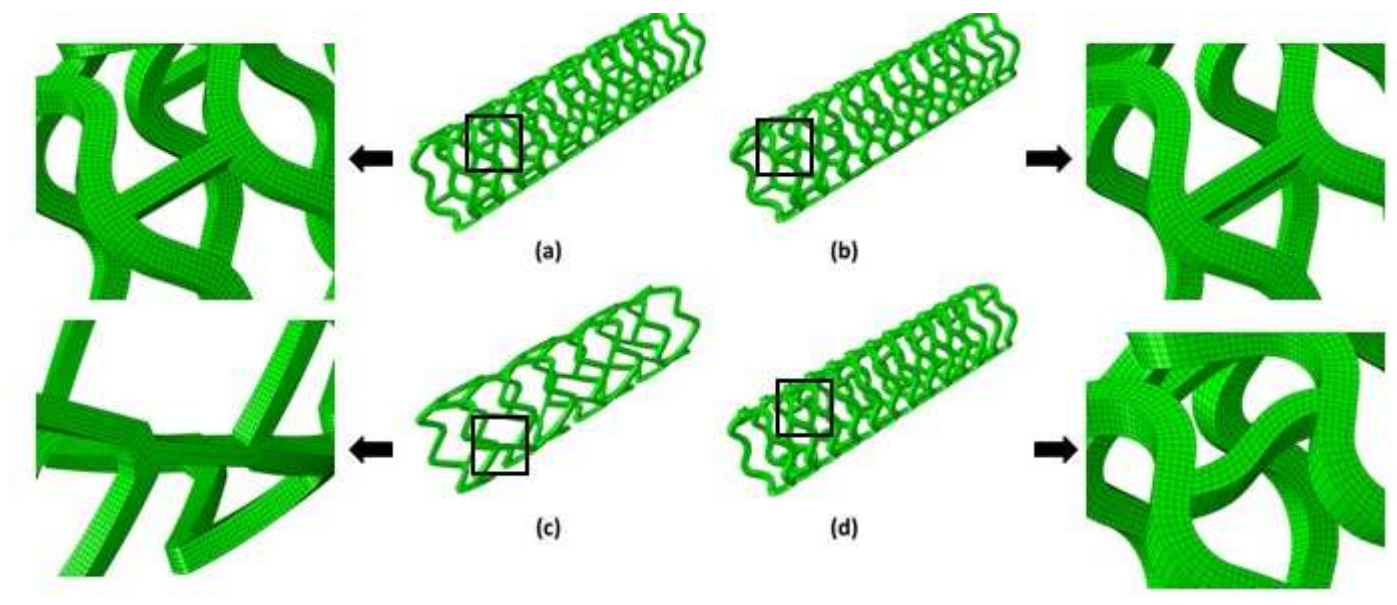

Figure 1, 3D models for (a) Absorb, (b) Elixir, (c) Igaki-Tamai and (d) RevaMedical stents with mesh.

Table 1, Summary of parameters and dimensions for the four stents.

\begin{tabular}{|c|c|c|c|c|}
\hline Stents & Absorb & Elixir & Igaki-Tamai & RevaMedical \\
\hline Stent Length (mm) & 12.66 & 11.66 & 11.24 & 12.76 \\
\hline Strut Thickness $(\mu \mathrm{m})$ & 150 & 150 & 170 & 200 \\
\hline Strut Width $(\mu \mathrm{m})$ & 200 & 200 & 200 & 200 \\
\hline Number of Rings & 13 & 12 & 7 & 13 \\
\hline Number of Crests & 6 & 6 & 6 & 6 \\
\hline Radius of U-bend (mm) & 0.5 & 0.5 & 0.4 & 0.5 \\
\hline Amplitude of U-bend (mm) & 0.2 & 0.2 & 0.7 & 0.2 \\
\hline Axial Strut Length (mm) & 0.8 & 0.8 & 1 & 0.8 \\
\hline
\end{tabular}




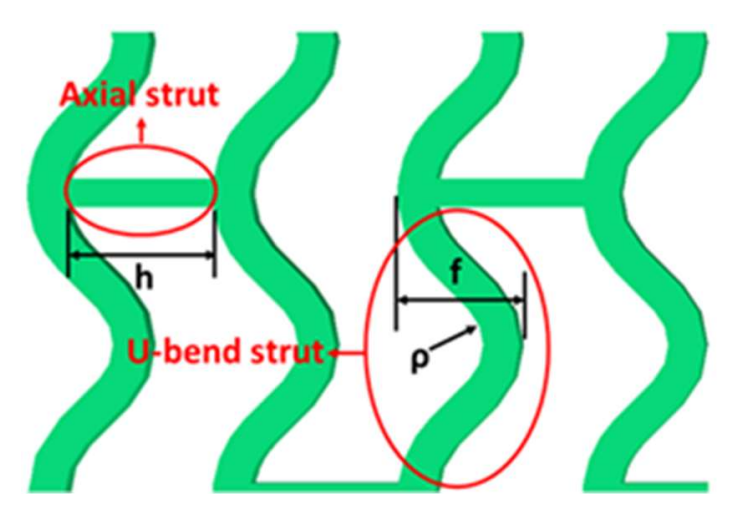

Figure 2, Stent design parameters, $\mathrm{h}$ is the axial strut, $\mathrm{f}$ is the amplitude of $\mathrm{U}$-bend strut and $\rho$ is the radius of $\mathrm{U}$-bend strut.

A three-layer artery was modelled, with an inner diameter of $3 \mathrm{~mm}$ and a length of 40 $\mathrm{mm}$. The overall thickness of arterial wall is $1 \mathrm{~mm}$, including $0.38 \mathrm{~mm}$ for adventitia layer, $0.33 \mathrm{~mm}$ for media layer and $0.29 \mathrm{~mm}$ for intima layer. The artery consists of three layers (adventitia, media and intima) according to histology analysis. The thickness of each layer was taken from Holzapfel et al. ${ }^{22}$, who measured 55 coronary artery samples from 13 patients. The length of artery was chosen to be $40 \mathrm{~mm}$ to mitigate the influence of boundary constraints in the finite element modelling ${ }^{23}$. 24 . Plaque was modelled as a symmetric wall inside the artery, with a length of $10 \mathrm{~mm}$ and a stenosis of $50 \%$ (inner diameter is $1.5 \mathrm{~mm}$ ). Hexahedral element with reduced integration (C3D8R) was used to mesh the artery and plaque. In the radial direction, the artery was meshed with 4 layers of elements for each arterial layer and the plaque was meshed with 8 layers of elements. In the longitudinal direction, the element size along the artery was increasing from the middle to both ends using a biased-seeding method. Figure 3 shows the mesh and geometry for plaque-artery system. 


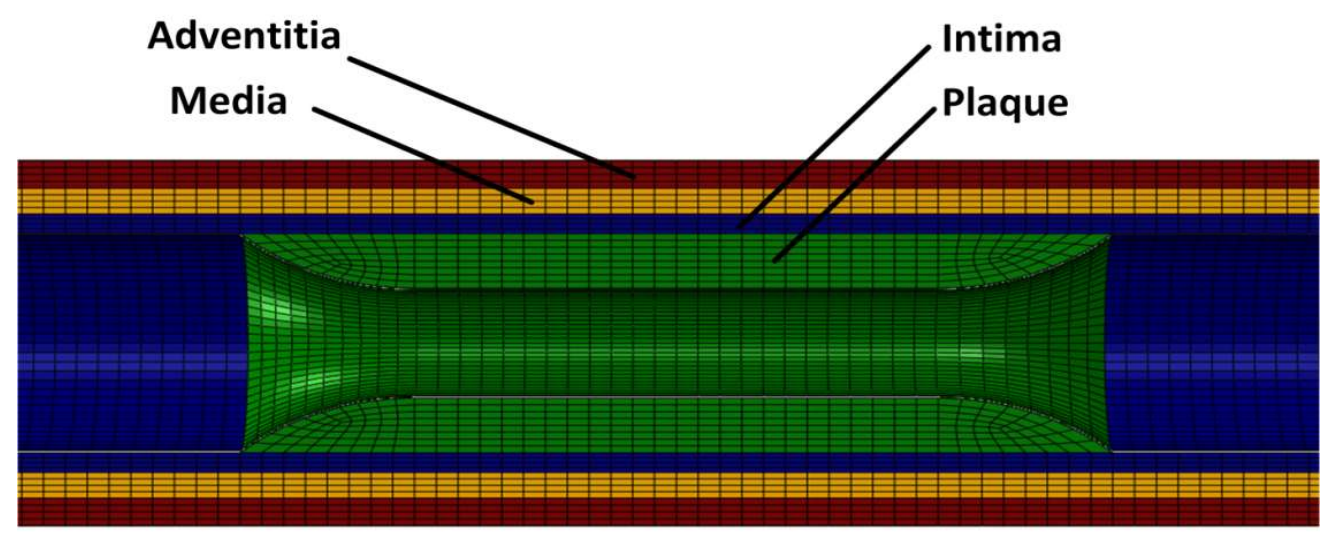

Figure 3, FE mesh for the plaque-artery system.

\subsection{Constitutive models for stent and stenotic artery}

In this study, biodegradable polymer PLLA was taken as the material for all four stents.

The mechanical behavior of bioresorbable polymer PLLA used in the finite element model of stent was described by the uniaxial tensile stress-strain curve, which consisted of both elastic and plastic deformation. For elastic deformation, Young's Modulus (2200 $\mathrm{MPa}$ ) and Poisson's ratio (0.3) were used in the simulation. Plastic deformation was considered by providing the yield stress as a function of plastic strain (i.e., isotropic hardening), extracted from the stress-strain curve in Pauck and Reddy ${ }^{2}$. In addition, the density of material PLLA is $1.4 \times 10^{-6}$.

For the three-layer artery, the Gasser-Ogden-Holzapfel mode ${ }^{25,26}$ was used to describe the anisotropic behaviour of the arterial layers with collagen fibers, and the strain energy potential function is expressed by: 


$$
\begin{aligned}
& \mathrm{U}=\mathrm{C}_{10}\left(\mathrm{I}_{1}-3\right)+\frac{1}{\mathrm{D}}\left(\frac{(\mathrm{J})^{2}}{2}-\ln ^{\mathrm{J}}\right)+\frac{\mathrm{k}_{1}}{2 \mathrm{k}_{2}} \sum_{\alpha=1}^{\mathrm{N}}\left[\exp \left(\mathrm{k}_{2}\left\langle\mathrm{E}_{\alpha}\right\rangle^{2}\right)-1\right] \\
& \mathrm{E}_{\alpha}=\kappa\left(\mathrm{I}_{1}-3\right)+(1-3 \kappa)\left[\mathrm{I}_{4(\alpha \alpha)}-1\right]
\end{aligned}
$$

where $\mathrm{U}$ is the strain energy per unit of reference volume, $\mathrm{C}_{10}, \mathrm{D}, \mathrm{k}_{1}, \mathrm{k}_{2}$ and $\mathrm{\kappa}$ are temperature-dependent material parameters, $\mathrm{N}$ is the number of fiber families, $\mathrm{I}_{1}$ is the first deviatoric strain invariant, $\mathrm{J}$ is the elastic volume ratio, $\mathrm{I}_{(4(\alpha \alpha))}$ is the invariant of Cauchy-Green deformation tensor and $E_{\alpha}$ represents the deformation of the fiber families. The operator $<>$ stands for the Macauley bracket.

The constitutive model was calibrated by fitting the averaged stress-stretch curves obtained form 13 patients ${ }^{22}$, and the calibrated parameter values for the Gasser-Ogden-Holzapfel model were given in Table 2. In this study, it is assumed that there are two families of collagen fibers embedded in a soft incompressible ground matrix within each arterial layer, i.e., $\mathrm{N}=2$. The parameter $\gamma$ in Table 2 (related to $\mathrm{I}_{4(\alpha \alpha)}$ in Eq. (1)) represents the angle between the mean orientation of the fibers and the circumferential direction, so it is measured from the circumferential direction. The values of $\gamma$ were taken from Holzapfel et al. ${ }^{22}$, who gave an average value for arterial layer samples taken from 13 patients. It should be noted that the $\gamma$-parameter values given in Holzapfel et al. ${ }^{22}$ may not represent exactly the same mean fiber orientation as those in the Gasser-Ogden-Holzapfel model ${ }^{26}$, but they have similar physical meanings. The parameter $\kappa$ in Eq. (1) represents the level of fiber dispersion, which was firstly introduced in the Gasser-Ogden-Holzapfel model by Gasser et al. ${ }^{26}$. It is believed that 
fiber distribution varied significantly from patients to patients. As direct measurements of fiber distribution were not available for the patients studied in Holzapfel et al. ${ }^{22}$, the calibration of parameter $\kappa$ was purely based on comparison of the simulated stress-stretch response, in both circumferential and longitudinal directions, against the experimental data reported in Holzapfel et $\mathrm{al}^{22}$. So the values of parameter $\kappa$ in Table 2 may not reflect the actual fiber dispersion in the tissue. Nevertheless, the values in Table 2 were able to give a matched description of the anisotropic response of the tissue (circumferential and longitudinal direction), as shown in Figure 4. Also in this work, we studied the stress distributions at a macroscopic level instead of fiber level, therefore the calibrated model should be able to capture the response of the tissue properly. In future work, the value of $\kappa$ should be assessed against histological data of fiber distribution in arterial layers.

It should be noted that the Gasser-Ogden-Holzapfel model ${ }^{26}$ incorporates fiber dispersion, but it may cause some unphysical behavior due to the treatment of fiber tension-compression behavior under deformation in which the fibers under compression cannot be excluded correctly. To resolve this issue, Holzapfel and Ogden ${ }^{27}$ introduced a tension-compression switch to the model, which neglects the contribution of fibers under compression. Specifically, they applied an angular integration approach to model the distribution of dispersed fibers, and computational studies showed that the exclusion of the compressed fibers made a significant difference to the elastic response of the tissue $^{28}$. Recently, they also introduced a discrete fiber dispersion model to exclude fibers 
under compression (i.e., in a discrete manner), and computational implementation of this model produced accurate results for a unit cube under simple tension and shear as well as for a rectangular strip under non-homogeneous uniaxial extension ${ }^{29}$. This will need to be considered in future simulations of stent deployment in diseased artery.

For hypocellular plaque, the constitutive behaviour was defined in the form of first-order hyperelastic Ogden strain energy potential ${ }^{30}$, and the material parameters were calibrated against experimental data ${ }^{31}$. Further details, regarding the model parameters and comparison between model simulations and experimental data, can be found in our previous study ${ }^{6,32}$.

Table 2, Parameter values of the anisotropic hyperelastic Gasser-Ogden-Holzapfel model $^{6}$.

\begin{tabular}{ccccccc}
\hline Parameters & $\begin{array}{c}C_{10} \\
(\mathrm{MPa})\end{array}$ & $\begin{array}{c}\boldsymbol{D} \\
\left(\mathrm{MPa}^{-1}\right)\end{array}$ & $\begin{array}{c}\boldsymbol{k}_{1} \\
(\mathrm{MPa})\end{array}$ & $\boldsymbol{k}_{2}$ & $\boldsymbol{\kappa}$ & $\gamma$ \\
\hline Adventitia & $8.32 \mathrm{E}-3$ & $4.67 \mathrm{E}-6$ & 1 & 1000 & 0.303 & $67^{\circ}$ \\
Media & 0.005 & $5.31 \mathrm{e}-6$ & 0.57 & 80 & 0.313 & $20^{\circ}$ \\
Intima & 0.03 & $8.95 \mathrm{E}-7$ & 4 & 1200 & 0.303 & $60^{\circ}$ \\
\hline
\end{tabular}



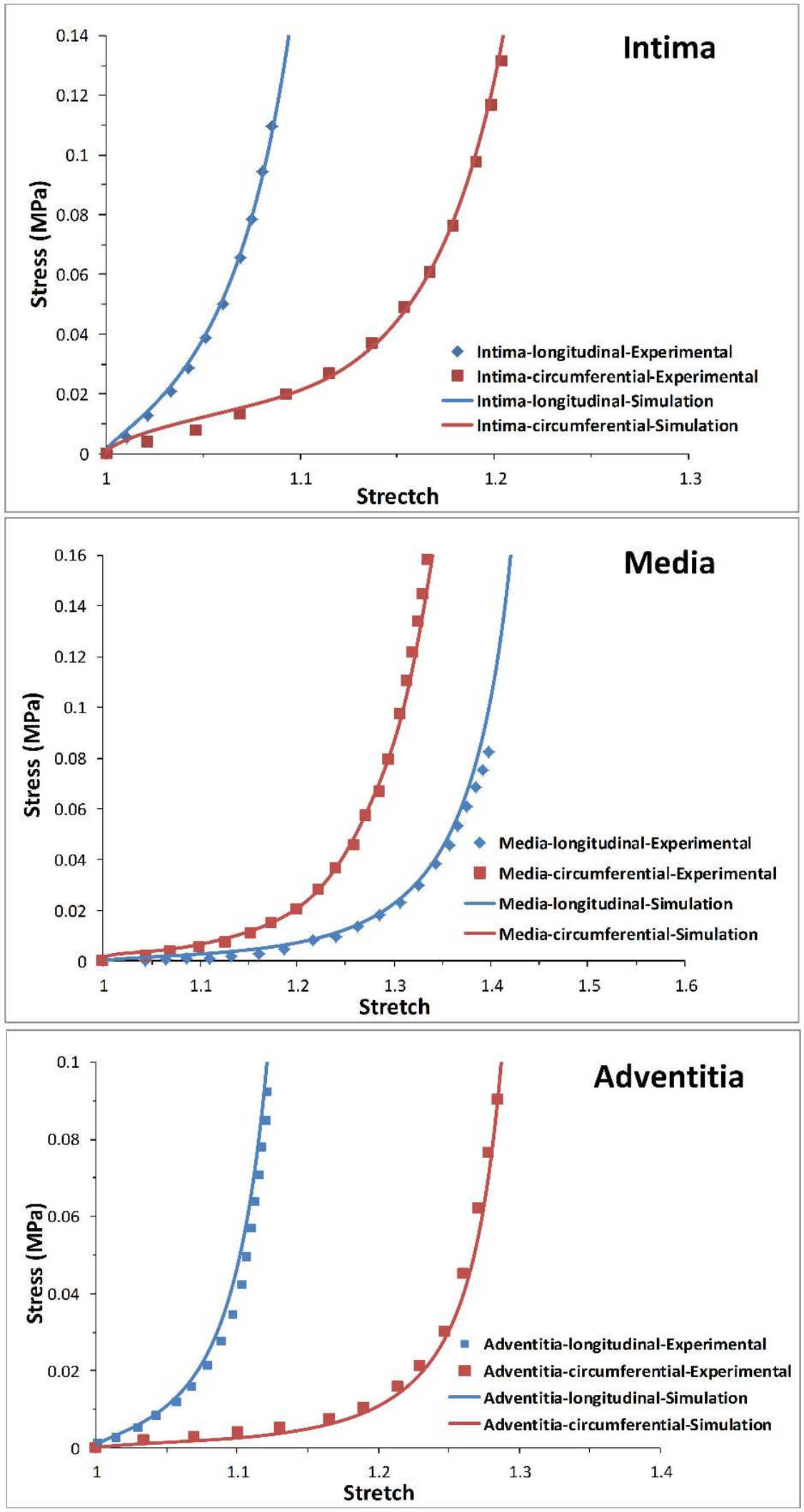

Figure 4, Longitudinal and circumferential stress-stretch responses: simulation results $v$ s. experimental data. 


\subsection{Modelling of stent deployment}

Simulation of stent deployment was divided into four steps: crimping, spring back, balloon inflation and deflation. The stent was crimped onto the tri-folded balloon by applying enforced displacement on the 12 rigid plates constructed around the stent. After crimping, the rigid plates were removed to allow the recovery of elastic deformation for the crimped stent. The inflation step was performed by applying pressure on the inner surface of balloon. The uniform pressure was linearly increasing from 0 to $1.4 \mathrm{MPa}$. Both ends of artery were fully constrained to reflect the constraint imposed by the human body environment. Interactions between the artery, stent and balloon were modelled as surface to surface hard contacts with a frictional coefficient of 0.25 . The deflation step was modelled by linearly releasing the pressure on the inner surface of balloon, which allowed the expanded stent to recoil freely. Interactions between stent, the balloon and the plaque were maintained in this step.

It should be noted that the residual stress in the arterial wall can be considered with a generalized prestressing algorithm reported in Pierce et $\mathrm{al}^{33}$. Specifically, an incremental update of displacement field in the classical approach is replaced by an incremental update of displacement gradient ${ }^{34,35}$. This method allows for an incorporation of residual stresses into the finite element model without changing the original geometry ${ }^{33}$. However, the residual stress of the arterial wall was not considered in our model, a limitation of the current study. Further research is required to incorporate the residual stress appropriately into our simulations. 


\subsection{Fatigue deformation analysis}

In order to study fatigue behaviour of stent under pulsatile blood pressure, two simulation steps, i.e., pre-loading and cyclic loading steps, were added following the deployment of stent. During these two steps, contact between stent and balloon was removed while contact between stent and artery was maintained. Both ends of artery were still fully constrained over the process. Normally, the realistic blood pressure has a mean value of $100 \mathrm{mmHg}(0.0125 \mathrm{MPa})$, fluctuating between a diastolic value of 80 $\mathrm{mmHg}(0.01 \mathrm{MPa})$ and a systolic value of $120 \mathrm{mmHg}(0.015 \mathrm{MPa})$. In this study, the systolic-diastolic blood pressure followed a realistic waveform. Figure 5 shows the pressure pulse at the inlet of ascending aorta under normal pressure condition, which was taken from Vasava et $\mathrm{al}^{36}$. The time for single heart beat is $0.85 \mathrm{~s}$, and the waveform includes two peaks in one cycle. In the pre-loading step, blood pressure was applied on the inner surfaces of both stent and artery with a linear increase from zero to $0.01 \mathrm{MPa}$ (diastolic value), and then diastolic-systolic pressure loading was imposed to simulate cyclic deformation of the system (i.e., cyclic loading step).

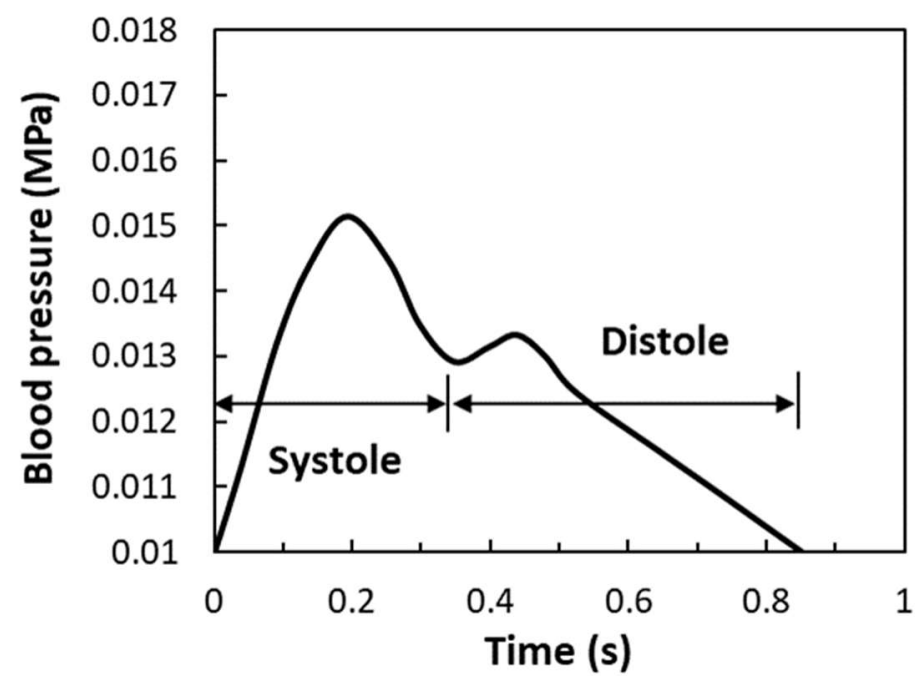

Figure 5, Blood pressure in the realistic waveform under normal condition ${ }^{36}$. 


\section{Results}

\subsection{Stent expansion}

Stent expansion has been monitored by tracking the diameter change against radial pressure for four stents during deployment process (Figure 6). Generally, the stent diameter increases slightly during the initial inflation stage, followed by a fast expansion stage and then a saturation stage with the increasing pressure. The four stents experience different expansion rates during balloon inflation process. The Igaki-Tamai stent expands with the highest rate and reaches saturation earliest (at a pressure of $0.2 \mathrm{MPa}$ ), while the RevaMedical stent expands with the lowest rate and reaches saturation latest (at a pressure of $0.8 \mathrm{MPa}$ ). The Absorb and Elixir stents show similar expansion behaviour, and reach saturation at a pressure of $0.6 \mathrm{MPa}$. At the peak inflating pressure, the Igaki-Tamai stent achieves a diameter of $2.96 \mathrm{~mm}$, while the RevaMedical stent expands to a diameter of $2.62 \mathrm{~mm}$. The achieved diameter is $2.68 \mathrm{~mm}$ for the Elixir stent and $2.70 \mathrm{~mm}$ for the Absorb stent. After releasing the balloon pressure, stent diameter experiences a gradual decrease in all cases, leading to a recoiling effect. This is caused by the recovery of elastic deformation of the stents during expansion. As shown in Figure 7, the recoiling effect is $17 \%$ for the Absorb and Elixir stents, $23 \%$ for the Igaki-Tamai stent and $15 \%$ for the RevaMedical stent. After balloon deflation, the final diameter is measured to be $2.22 \mathrm{~mm}$ for the Absorb stent, $2.20 \mathrm{~mm}$ for the Elixir stent, $2.28 \mathrm{~mm}$ for the Igaki-Tamai stent and $2.25 \mathrm{~mm}$ for the RevaMedical stent. 


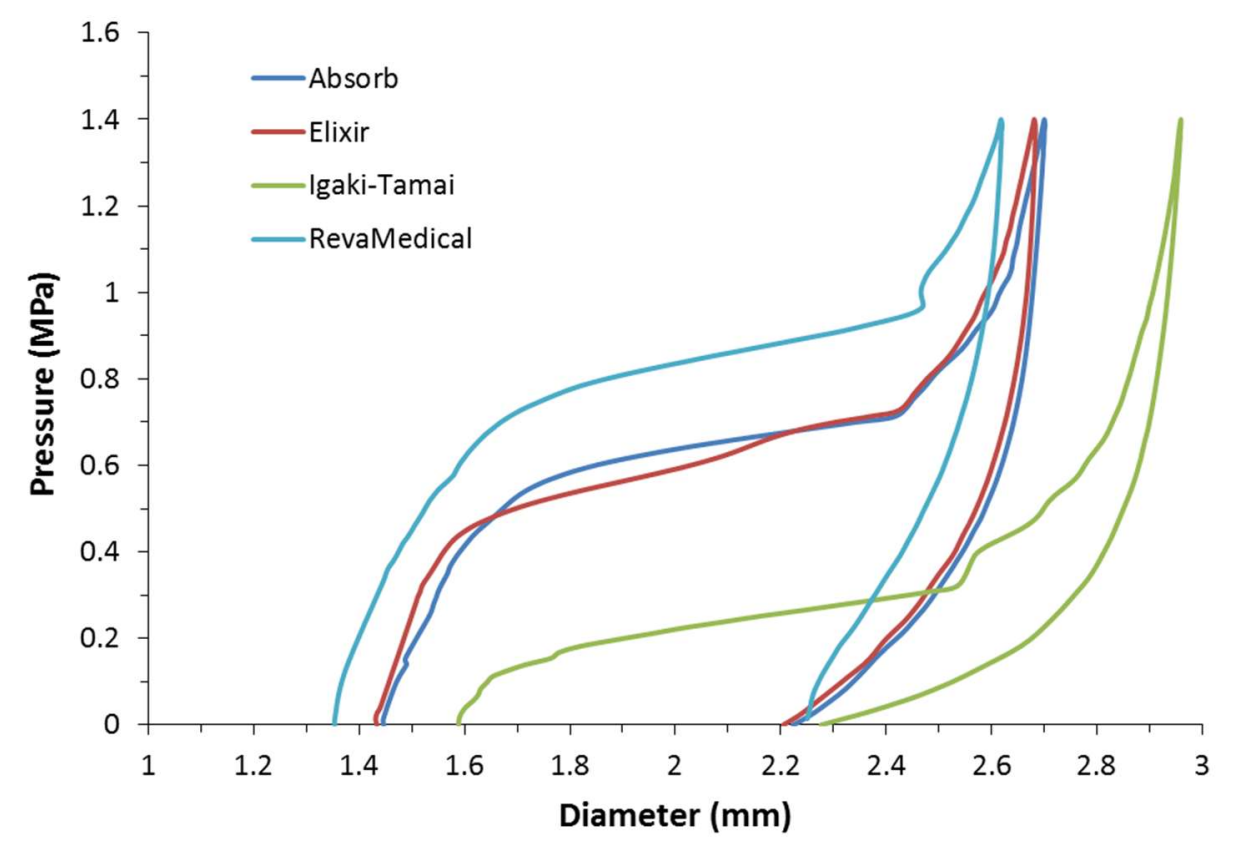

Figure 6, Diameter change against pressure for the four stents during deployment.

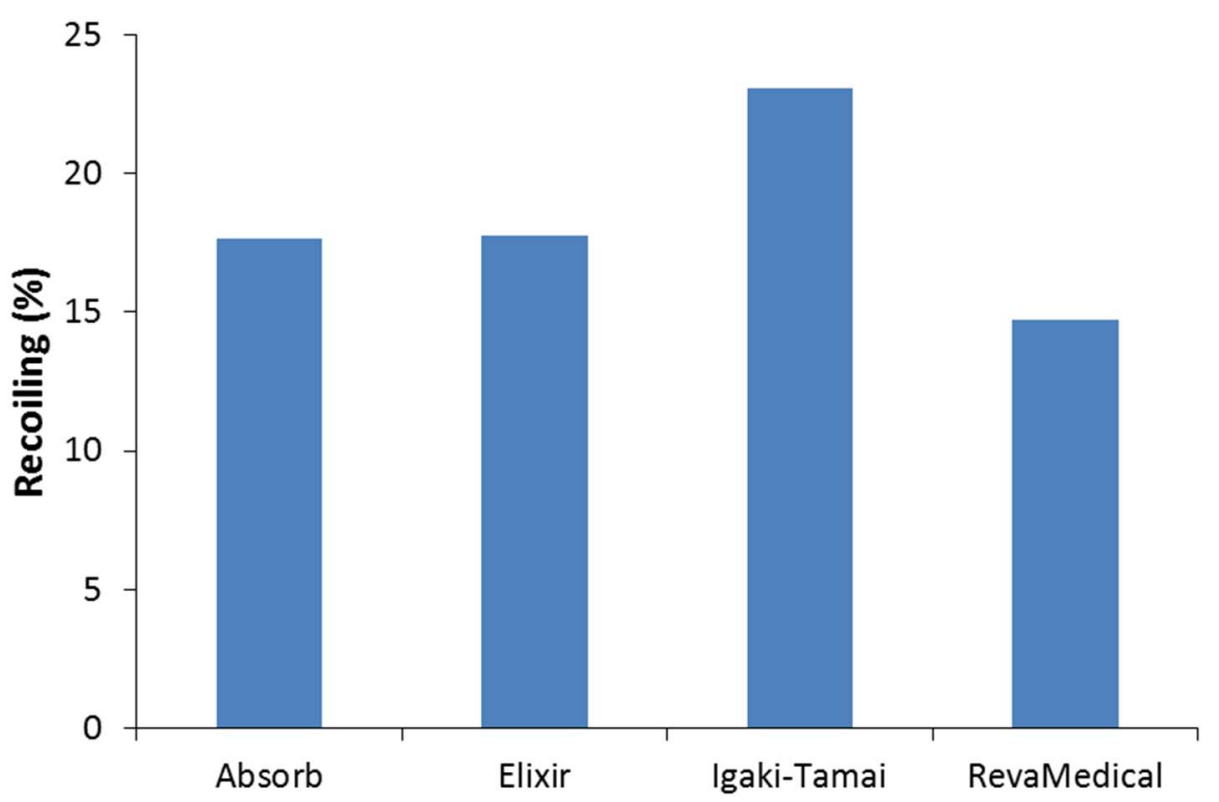

Figure 7, Recoiling effects for the four stents after balloon deflation. 
The stresses developed in the four stents after deployment are compared in Figure 8 via contour plots of von Mises stress. Significant level of stress has been developed in the stent in all cases, with a maximum value of around $100 \mathrm{MPa}$. Stress concentrations are located at the crests of U-bends, as indicated by red colour.

Also, all four stents show the dogbone shapes caused by the nonuniform expansion of the stents. Dogboning effect is mainly caused by the shrinkage of the plaque after balloon deflation, which becomes the most severe at the middle of the plaque due to the confinement of surrounding tissue (i.e., bulk constraint). This imposed the most radial compression to the middle part of the stent, leading to the dogboning effect. In addition, the length of stent is always longer than that of plaque, which also contributes to the dogboning effect as the ends of stent experience less radial compression after deployment. he dogbonig effect is determined by calculating the difference between diameters in the middle and at the end ${ }^{37}$ :

$$
\operatorname{dog} \text { boning }(\%)=\frac{\left(d_{e}-d_{m}\right)}{d_{m}} \times 100 \%
$$

where $d_{e}$ is the average diameter at the end of stent and $d_{m}$ is the average diameter in the middle of stent. As shown in Figure 9, the Absorb and Elixir stents experience the most severe dogboning (i.e., 35\%), while the RevaMedical stent has the least dogboning effect (i.e., 17\%). The Igaki-Tamai stent shows a dogboning of $23 \%$. 
(a)

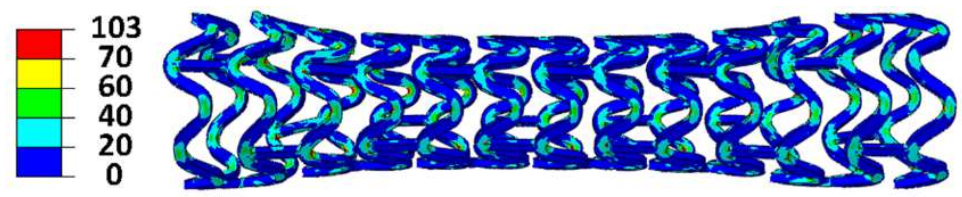

(b)

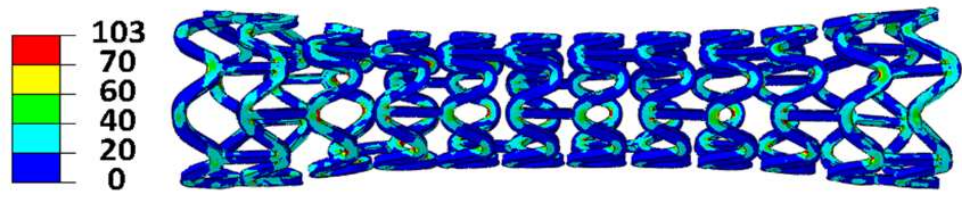

(c)
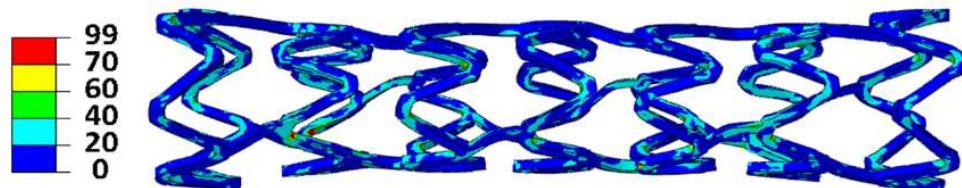

(d)

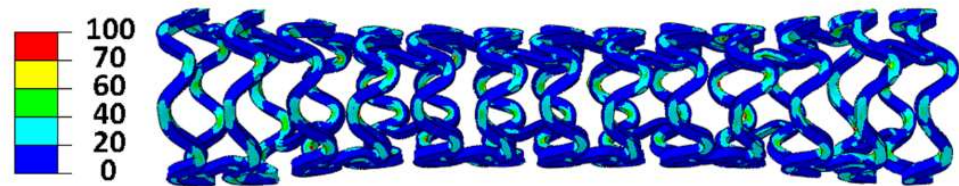

Figure 8, Contour plots of von Mises stress (MPa) for the four stents after balloon deflation.

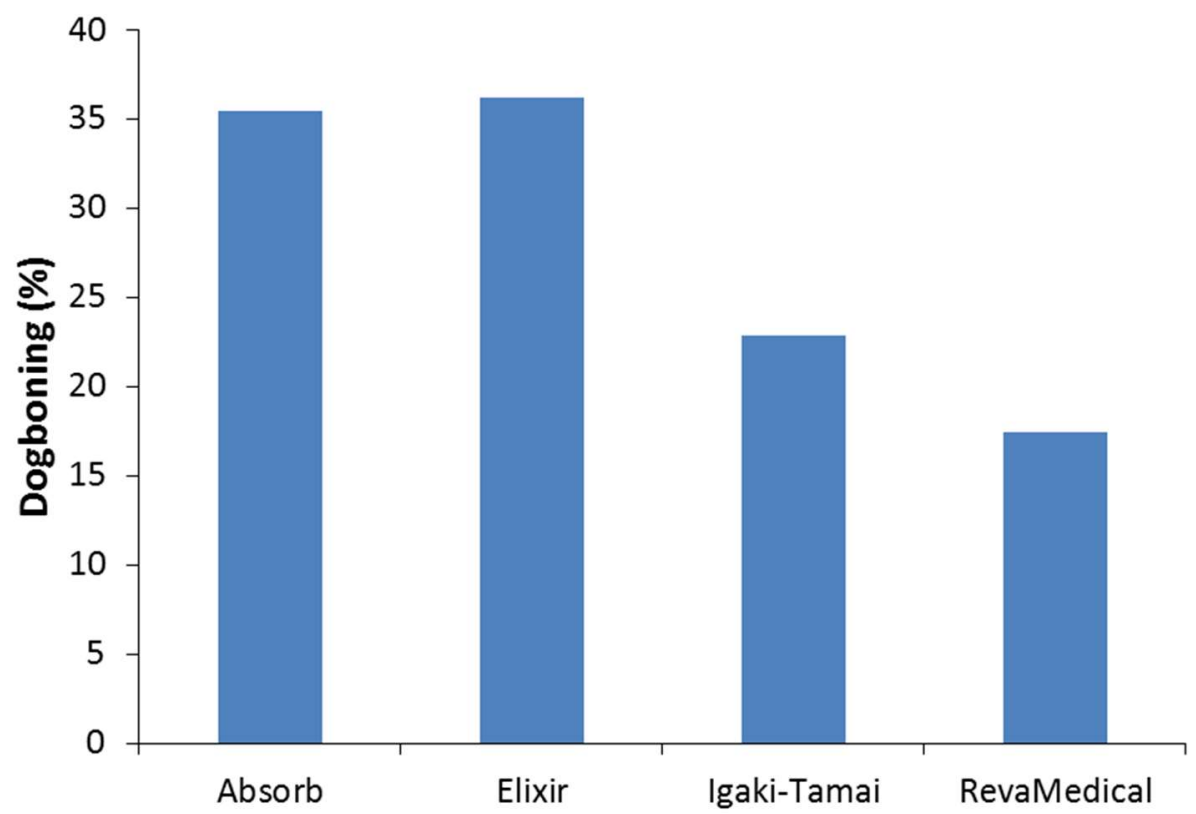

Figure 9, Dogboning effects for the four stents after balloon deflation. 


\subsection{Stresses in the plaque/artery}

Figures 10 and 11 show the von Mises stress contour plot on the plaque and artery at peak inflating pressure during the deployment of the four stents. The maximum von Mises stress on the plaque was 3.91 MPa for the Absorb stent, 3.83 MPa for the Elixir stent, 5.88 MPa for the Igaki-Tamai stent and 3.46 MPa for the RevaMedical stent. The maximum von Mises stress on the artery was $15.30 \mathrm{MPa}$ for the Absorb stent, $15.85 \mathrm{MPa}$ for the Elixir stent, $20.19 \mathrm{MPa}$ for the Igaki-Tamai stent and $13.80 \mathrm{MPa}$ for the RevaMedical stent. The high levels of stresses on plaque and arterial layers suggested a potential damage in the native tissue of arterial wall during stent deployment, and therefore damage of arterial wall should be considered in order to properly capture the deformation characteristics of the vessel. This requires a significant amount of additional efforts, in terms of formulating a new constitutive model for the tissue, which is beyond the scope of current study.

(a)

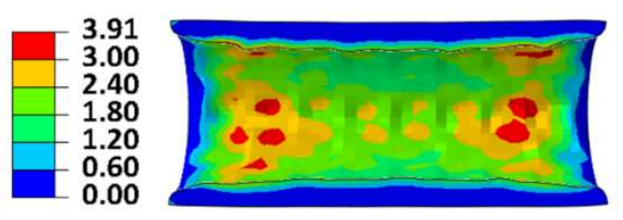

(b)

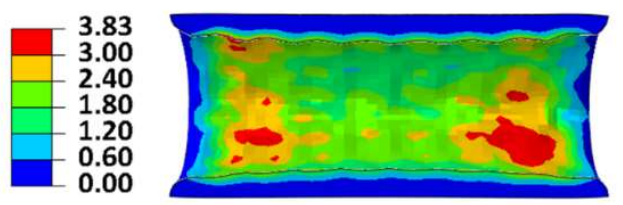

(c)

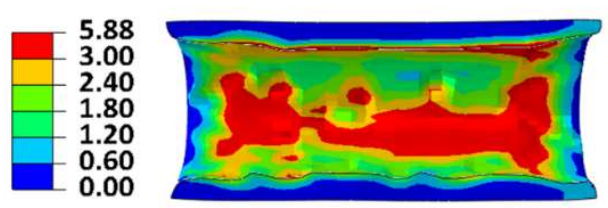

(d)

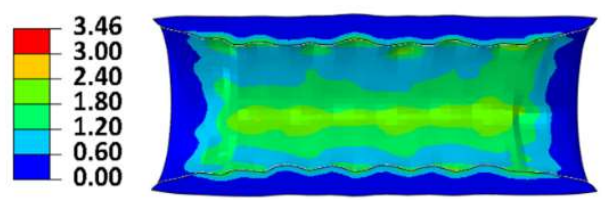


Figure 10, The von Mises contour (MPa) plot on plaque at peak pressure: (a) Absorb, (b) Elixir, (c) Igaki-Tamai and (d) RevaMedical stents.

(a)

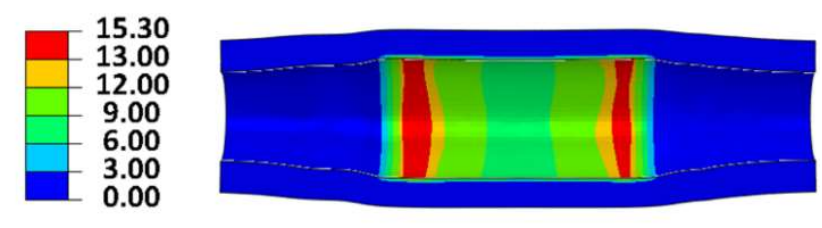

(b)
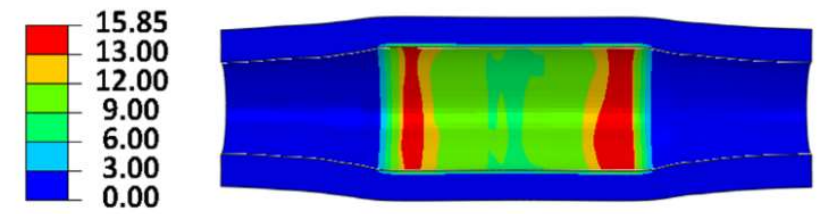

(c)
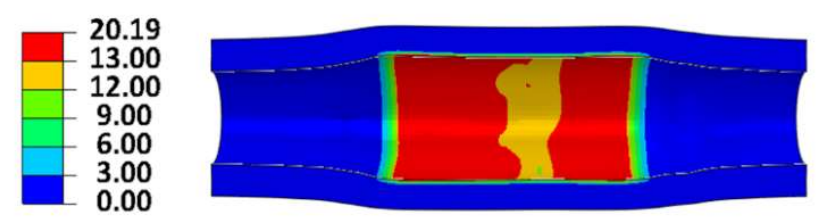

(d)
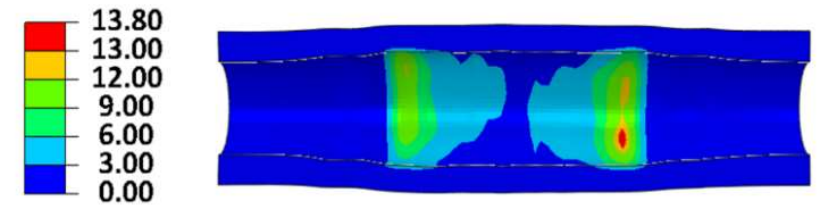

Figure 11, The von Mises contour ( $\mathrm{MPa}$ ) plot on three-layer artery at peak pressure: (a)

Absorb, (b) Elixir, (c) Igaki-Tamai and (d) RevaMedical stents.

High levels of stresses have also been developed in the plaque and artery following the stenting process. For the plaque (Figure 12), stress concentration is noticed at both ends of the plaque. The maximum von Mises stress on the plaque is $1.04 \mathrm{MPa}, 0.89 \mathrm{MPa}, 1.41$ $\mathrm{MPa}$ and $1.35 \mathrm{MPa}$ for the Absorb, Elixir, Igaki-Tamai and RevaMedical stents, respectively. For the artery (Figure 13), the stress has a visible gradient from the intima layer to the adventitia layer. Stress concentration is mainly located in the intima layer of the artery in all four simulations. The maximum von Mises stress is $0.17 \mathrm{MPa}, 0.16 \mathrm{MPa}$, 0.40 MPa and 0.29 MPa for the artery expanded with the Absorb, Elixir, Igaki-Tamai and RevaMedical stents, respectively. 
(a)

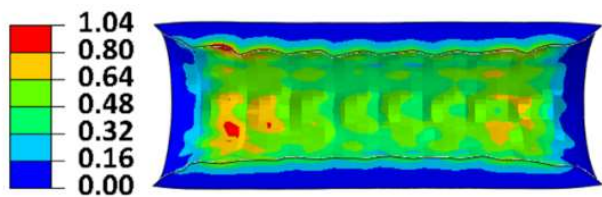

(b)

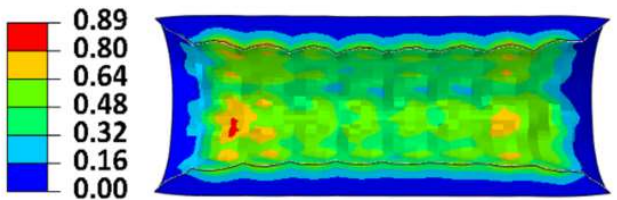

(c)

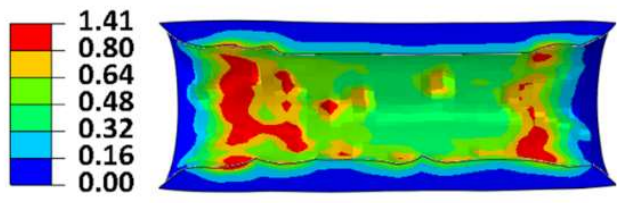

(d)

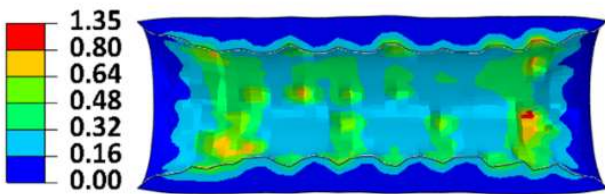

Figure 12, The von Mises contour (MPa) plot on plaque after balloon deflation: (a)

Absorb, (b) Elixir, (c) Igaki-Tamai and (d) RevaMedical stents.

(a)
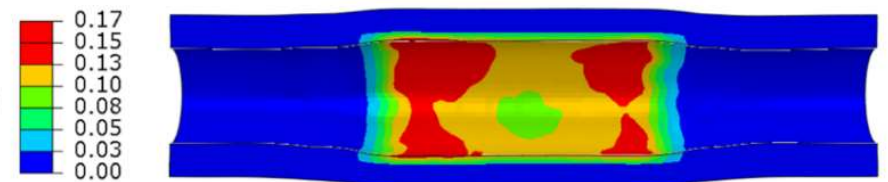

(b)
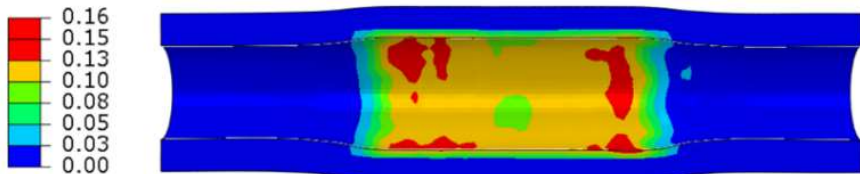

(c)
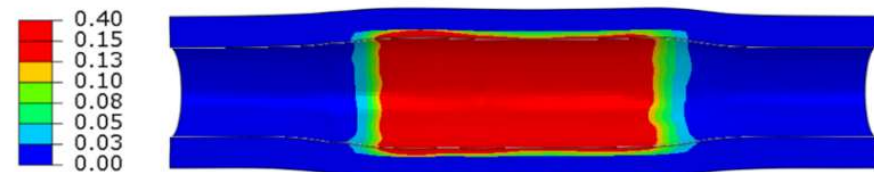

(d)
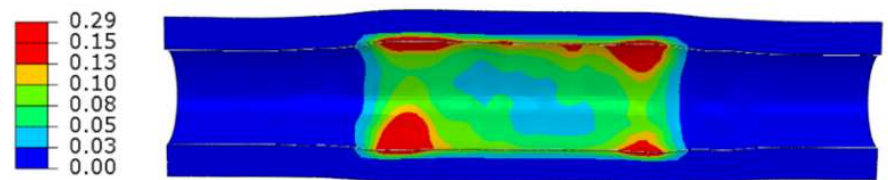

Figure 13, The von Mises contour (MPa) plot on the three-layer artery after balloon 
deflation: (a) Absorb, (b) Elixir, (c) Igaki-Tamai and (d) RevaMedical stents.

\subsection{Stent deformation due to pulsatile blood pressure}

During the cyclic systolic-diastolic loading step, the maximum von Mises stress is located at critical element $\mathrm{A}$ and the maximum equivalent plastic strain occurs at critical element B, as indicated in Figure 14. In order to investigate the fatigue behaviour of stent, stress variations of these two elements are required. Figure 15 shows the von Mises stress variation against step time for the critical element A subjected to cyclic systolic-diastolic loading. It is clear that the von Mises stress shows a significant fluctuation under the cyclic systolic-diastolic loading and intend to stabilize at cycle 5. The maximum and minimum stabilized stresses are $100 \mathrm{MPa}$ and $92 \mathrm{MPa}$, respectively, which gives a stress amplitude of $4 \mathrm{MPa}$ (i.e., a stress range of $8 \mathrm{MPa}$ ).

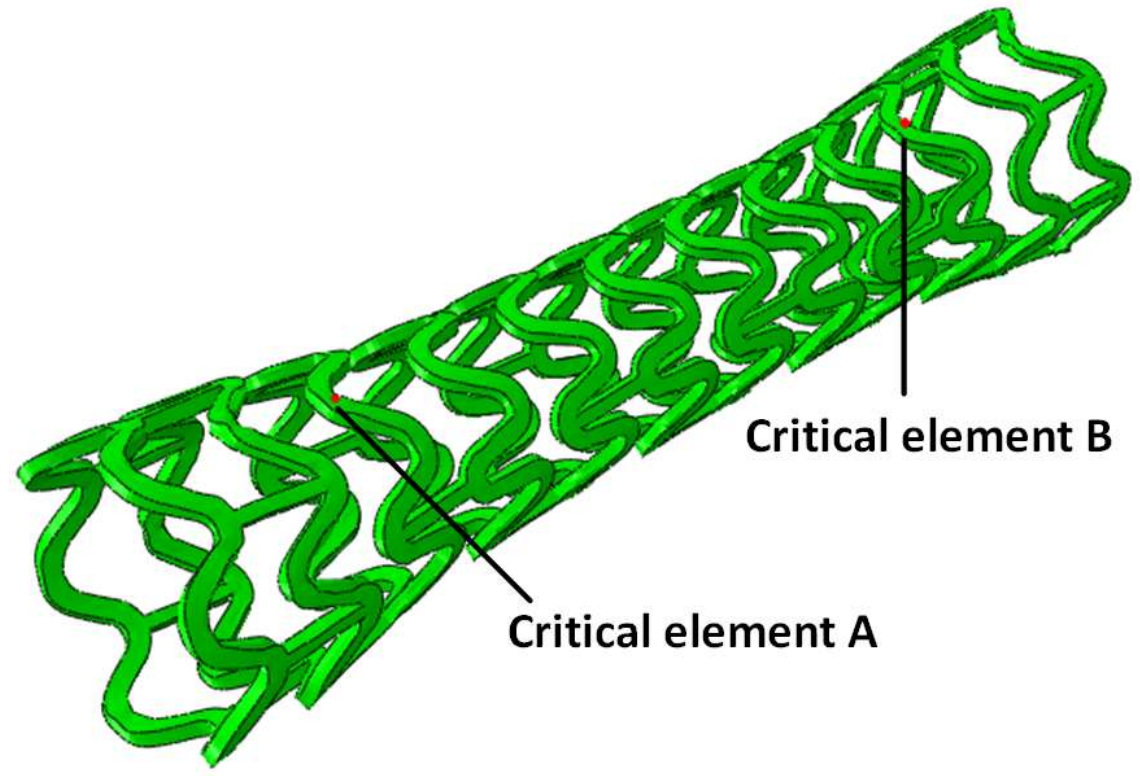

Figure 14, Stent model showing locations of critical elements A and B with maximum von Mises stress and with maximum equivalent plastic strain, respectively. 


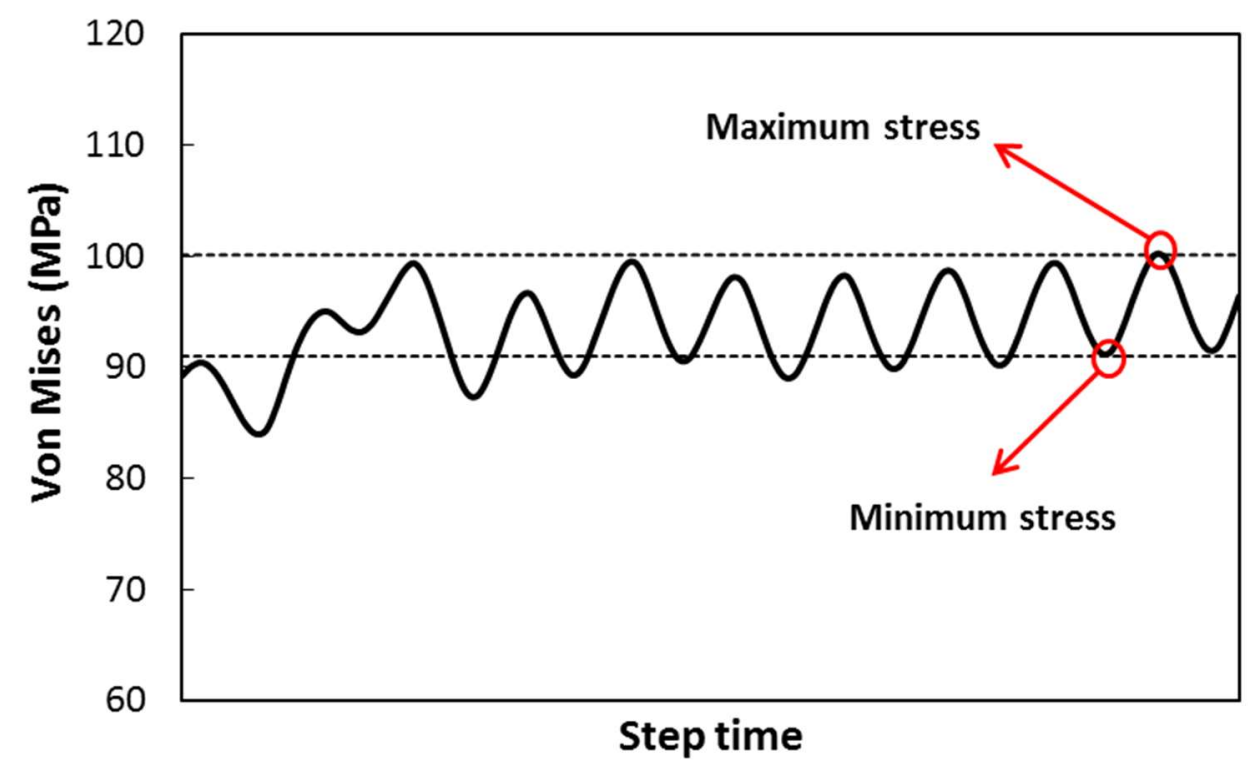

Figure 15, Diagram of von Mises stress variation for critical element A during systolic-diastolic cyclic loading process.

\subsection{Fatigue life assessment}

Fatigue life prediction is of importance because cyclic load may lead to a failure of component at much lower stress compared to that under monotonic loading condition. Stress-life $(S-N)$ method is usually used to determine the fatigue life of materials and components. The fatigue testing data of polymer PLLA studied here are not available, and therefore the $S$-N curves of several other polymers are considered to estimate the fatigue life of Elixir stent, as shown in Figure $16^{38,39}$. The red line represents the stress amplitude of critical element on stent under cyclic systolic-diastolic loading condition, and the black lines illustrate the existing fitted $S$-N curves of polymers, including Epoxy (EP), polyethylene terephthalate (PET), poly-lactic acid (PLA), polystyrene (PS), polymethyl methacrylate (PMMA), polypropylene (PP), polyethylene (PE) and 
polytetrafluoroethylene (PTFE). The fatigue limit can be obtained for EP, PS and PP from the diagram, which was $20 \mathrm{MPa}, 10 \mathrm{MPa}$ and $5 \mathrm{MPa}$, respectively. The $S$-N curve of PLA does not exhibit a saturation stage, and therefore the specified fatigue limit cannot be determined. However, the fatigue limit of PLA can be assumed to be between those for polymer EP (20 MPa) and PP (5 MPa). The stress amplitude of critical element A can be calculated from the variation of von Mises stress, which is $4 \mathrm{MPa}$ and even lower than the fatigue limit of PP $(5 \mathrm{MPa})$. This suggests that critical element $\mathrm{A}$ is located within infinite life stress zone. It should be noticed that the fatigue life prediction is performed based on testing data up to $10^{7}$ cycles.

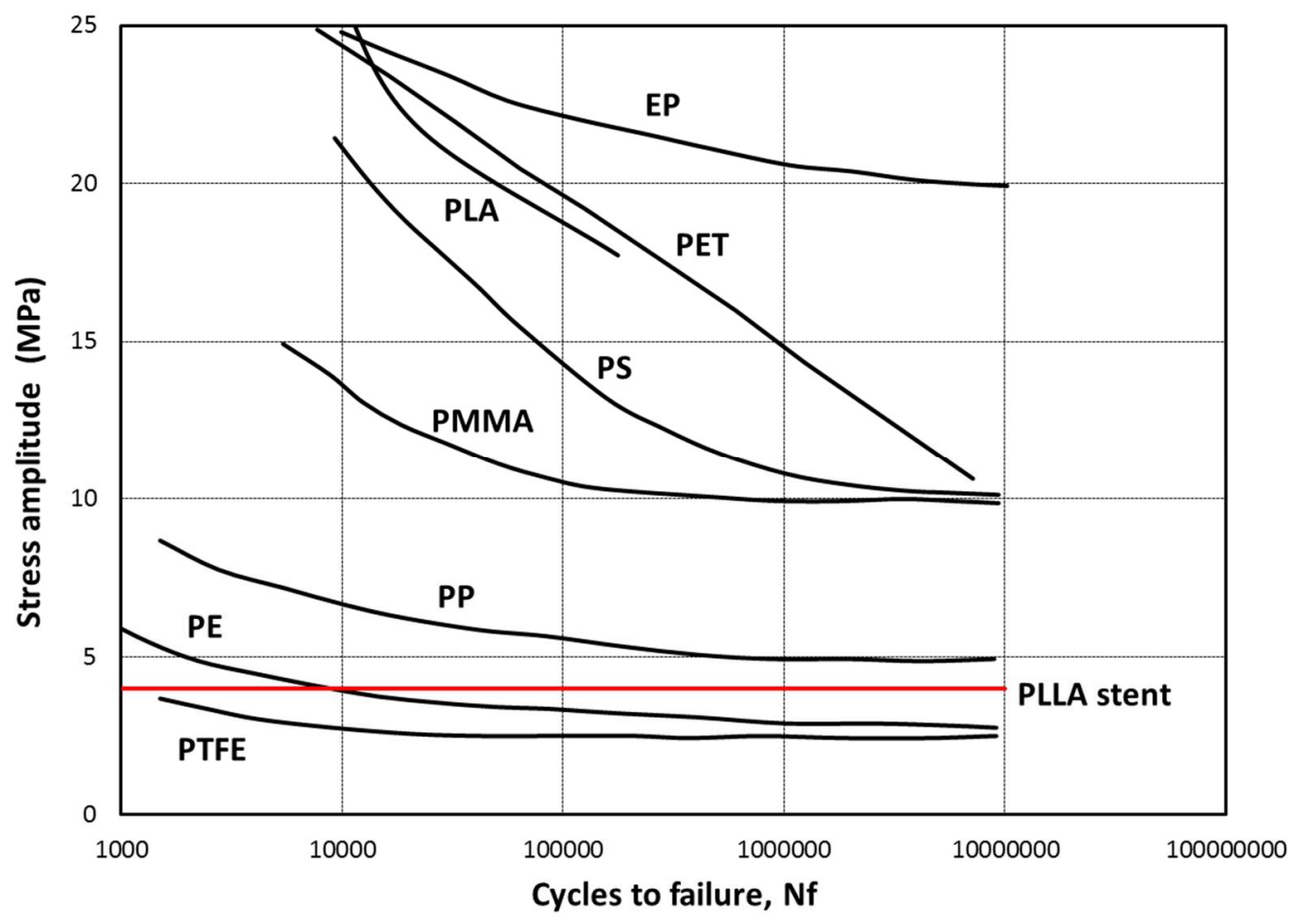

Figure 16, Stress amplitude vs. cycles to failure (S-N) curves for EP, PET, PLA, PS, PMMA, PP, PE and PTFE. 
The above analysis is only valid when the mean stress is zero. In FE analysis, a significant level of mean stress is obtained for stent due to excess deformation in the deployment stage. Consequently, the Goodman analysis method can be considered to assess the fatigue life of stent. The Goodman's rule combines the mean stress and stress amplitude, which is defined by:

$$
\frac{\sigma_{a}}{S_{a}}+\frac{\sigma_{m}}{S_{u}}=1
$$

where $\sigma_{m}$ and $\sigma_{a}$ represent the mean stress and stress amplitude of applied cyclic stress, and $S_{a}$ and $S_{u}$ are the fatigue limit (fatigue strength) and ultimate tensile strength of the material. The ultimate tensile strength of PLLA was taken as $105 \mathrm{MPa}$ based on the experimental data of Pauck and Reddy ${ }^{2}$.

The mean stress and stress amplitude of all elements can be obtained from the FE analysis of stent deformation during cyclic systolic-diastolic loading. They are plotted in the Goodman's diagram, as shown in Figure 17. The blue and orange lines represent the fatigue limit lines of PLLA, which were determined by estimating the fatigue limit in a range of $10 \mathrm{MPa}$ and $20 \mathrm{MPa}$. In fact, the fatigue limit for medical grade PLLA is not available. The range chosen here is based on the values reported for PLA (see Figure 16), where the S-N curve tends to reach a saturation at a stress amplitude between $10 \mathrm{MPa}$ and $20 \mathrm{MPa}$. Generally, the zone below fatigue limit line means safe zone, i.e., free from fatigue failure. The green square symbols represent the level of mean stress and stress amplitude of all elements and the red triangle symbol represents the critical element $\mathrm{A}$ which has the highest level of mean stress and stress amplitude. It can be observed that a 
large number of elements experience high levels of mean stress and stress amplitude during the cyclic systolic-diastolic loading. A group of elements are already located in the dangerous zone based on the estimated fatigue limit lines, and possess a risk of fatigue failure.

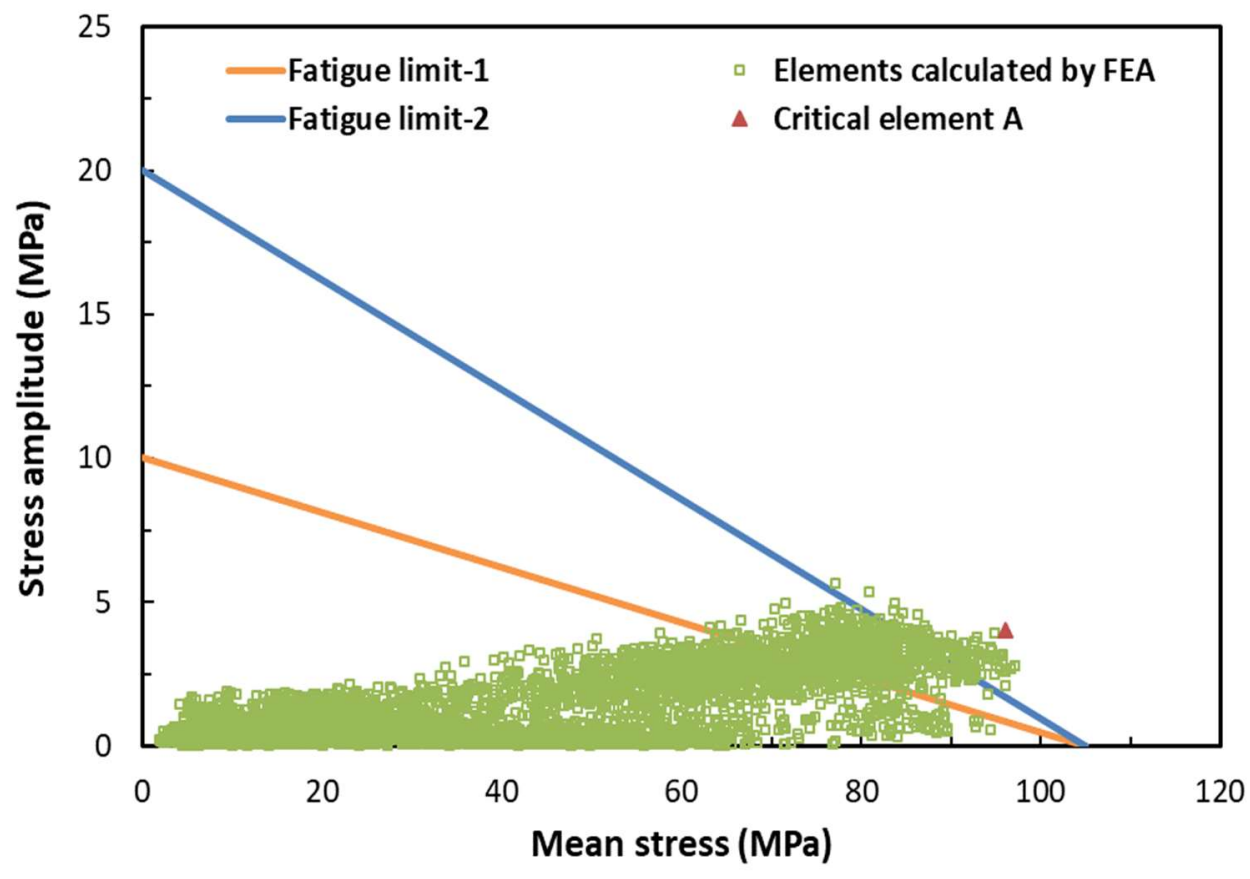

Figure 17, Goodman's diagram for the Elixir stent.

\section{Discussions}

\subsection{Effect of design on stent expansion}

The stent-diameter change against pressure shows differences for the four stents. The material properties are the same for all four stents, but they require different pressure to achieve the same diameter. For instance, to achieve a diameter of $2.5 \mathrm{~mm}$, the pressure required is $0.3 \mathrm{MPa}$ for Igaki-Tamai stent, 0.6 MPa for Elixir stent, 0.7 MPa for Absorb stent and $1 \mathrm{MPa}$ for RevaMedical stent. This indicates that design is an important factor 
that influences the expansion behavior of stent. Design of stent usually involves the shape, size and length of U-bend struts and axial struts. The radius and amplitude of U-bend strut make a difference to the radial expansion behavior of stent, and larger U-bend radius and amplitude make the stent easier to expand. The axial struts affect stent behavior in the longitudinal direction during expansion, and longer axial struts facilitate deformation in the axial direction during stent deployment.

Recoiling effect is observed for all stents after balloon inflation, and stents experience different recoiling effects due to their individual designs. Particularly, the Igaki-Tamai stent show the most severe recoiling effects when compared to the other three stents. It is because the Igaki-Tamai stent is made of sharper U-bend struts and longer axial struts, which makes it more flexible to deform during crimping and expansion processes. The Absorb and Elixir stents have the same U-bends and axial strut length, and therefore they experience almost the same recoiling effects. The RevaMedical stent has the same U-bend as the Absorb and Elixir stents, but its axial struts have a middle-to-middle connective design that enhances the stent rigidity, resulting in the lowest recoiling effect.

Similarly, the four stents experience different dogboning effects, which is mainly caused by design difference. For instance, the Absorb and Elixir stents have the almost same design, which results in almost the same dogboning effect (35\%). The Igaki-Tamai stent has longer axial strut and sharper U-bend strut, making it easier to expand and recover in the radial direction, thus less dogboning effect $(23 \%)$. For RevaMedical stent, it has the 
same U-bend strut as the Absorb and Elixir stents, but curved axial strut which gives it more freedom to deform and recover, and therefore a significantly reduced dogboning effect $(17 \%)$ is obtained after the deployment process.

\subsection{Stress distribution in the stent-artery system}

The stress states of stent-artery system also show some difference during the deployment of the four stents. The maximum von Mises stress are very close for all four stents during expansion processes, but less stress concentration areas are observed for the Igaki-Tamai stent due to its longer axial strut and larger amplitude of U-bends. With the distinct design, the Igaki-Tamai stent achieves the largest final diameter after balloon deflation, and thus contributes more expansion to the artery. As a result, the artery has the highest level of stresses during the deployment of the Igaki-Tamai stent. The Absorb and Elixir stents, with similar peak-to-peak connecting strut designs, induce the same degree of expansion to artery. A slightly less expansion of artery is generated during the deployment of RevaMedical stent, due to its middle-to-middle connecting strut design.

High level of stresses is generated in the plaque/artery during the deployment of stent. Timmins et al..$^{40}$ addressed that excessive vessel stresses induced by stenting might lead to adverse arterial reaction, damage and even restenosis. Bedoya et al. ${ }^{41}$ concluded that stent designs, with large axial strut spacing, blunted corners and large amplitudes of U-bends, would produce less stress concentration regions on the artery. In this study, the Igaki-Tamai stent, with long axial strut but sharp U-bend, generates more severe stress 
on the plaque/artery during its implantation in artery. It is due to the largest diameter achieved by the Igaki-Tamai stent during deployment process, facilitated by the longer axial and sharper U-bend struts in the stent design. So, stent design also plays an important role in the level of stresses induced to the artery/plaque during stent deployment.

\subsection{Fatigue behaviour of stent}

Firstly, stress concentration occurs at the inner corner of stent U-bends and low stress is found at the bridge struts during cyclic systolic-diastolic loading. This phenomenon is also reported in the study of fatigue of metallic stents. For instance, $\mathrm{Li}$ et al. ${ }^{19}$ studied fatigue behavior of $\mathrm{Co}-\mathrm{Cr}$ stent and found that the high stress areas were distributed in the curvatures of stent rings whereas minimal stress regions happened at the middle position of bridge struts. They predicted that the dangerous position of stent structure was at the curvature of rings due to the high stress levels, which was also verified by fatigue experiments. As discussed in the previous section, stress concentration occurs at the curvature (corner) of stent U-bends and high residual stress is generated during stent crimping and deployment processes. Thus, residual stress caused by stent expansion imposes a high level of mean stress, and acts as a key factor influencing the fatigue resistance of the stent structure in cyclic loading condition.

Fatigue life of stents usually refers to $10^{7}$ cycles due to the typical annual heart beating of $4 \times 10^{7}$ cycles/year. In this study, the fatigue life was assessed against a life of $10^{7}$ cycles 
using the $S$-N curves of selected polymers, and therefore the prediction is valid for at least a period of one year. The result is meaningful because the Elixir stent will degrade after one year. Certainly, fatigue behaviour of polymer can also be affected by environment, temperature and frequency of loading ${ }^{38}$. However, this study didn't consider the effect of temperature and frequency because the corresponding fatigue test data are not available. Therefore, to achieve comprehensive understanding of stent fatigue, further work is required, especially fatigue testing of PLLA and its structural components.

Moreover, the Goodman's rule has been used to conduct fatigue life prediction for stent, by evaluating the mean stress and stress amplitude distribution. In the Goodman's diagram, the fatigue limit line is determined by fatigue strength and ultimate tensile strength of the material. This study carried out fatigue life prediction of polymeric stent based on the stress state of all elements, and highlights that there is a risk of fatigue failure in the U-bend regions due to high levels of mean stress and stress amplitude. But for metallic stent (e.g. L605 Co-Cr alloy or 316L stainless steel), FE simulations suggested that there was no risk of fatigue failure under the systolic-diastolic loading condition $^{19,38}$. This may due to the difference in material properties. The L605 Co-Cr alloy and 316L stainless steel have significantly higher fatigue strength (300 MPa and 115 $\mathrm{MPa}$ ) and ultimate tensile strength (1390 $\mathrm{MPa}$ and $580 \mathrm{MPa})$, compared to polymer PLLA. This suggests that material properties, such as fatigue strength and ultimate tensile strength, also play an important role in the fatigue resistance of stents. On the 
other hand, it may also be due to the difference in the applied cyclic systolic-diastolic loads. Some of them considered the cyclic load that was applied on the outer surface of stent without an artery, and others included artery in the model but only applied cyclic loading on artery. In this study, cyclic systolic-diastolic load has been imposed on both the stent and artery which are in direct contact with the blood flow.

\subsection{Validation}

It should be noted that experimental data regarding stent deployment and post-implantation fatigue performance are not available for direct validation of our computational studies. However, comparisons were made against those reported for ABSORB stent in the work of Schiavone et al. ${ }^{24}$, which are in good agreement in terms of the stress distribution and magnitude on the stent. In our study, stent recoiling behavior was also compared with those reported in Pauck and Reddy ${ }^{2}$ for PLLA stent with similar design, and a good match was obtained (i.e., 35\% for ABSORB in this study vs. $31 \%$ for S1 stent in Pauck and Reddy ${ }^{2} ; 23 \%$ for Igaki-Tamai in this study vs. $22 \%$ for S3 stent in Pauck and Reddy ${ }^{2}$ ). In addition, stress distributions on stent are in good agreement with those reported in Debusschere et al. ${ }^{3}$ for a PLLA stent. In addition, fatigue analyses presented in this study are in good agreement with the work of Li et al. ${ }^{19}$, confirming the risk of strut U-bends to fatigue failure for both metallic and polymeric stents. For fatigue, Dreher et al. ${ }^{42}$ tested the fatigue life (up to $1.2 \times 10^{7}$ cycles) for a PLLA stent subunit (U-bend) subjected to displacement-controlled cyclic loading. The work confirmed the fatigue failure of U-bend unit, exhibiting a decreased life with increasing 
loading amplitude. In addition, it was also shown that fatigue loading significantly increased the chemical degradation rate of the PLLA stent, further promoting fatigue failure. Clinically, Yamaji et al. $^{43}$ reported that the leading mechanism for very late thrombosis was scaffold discontinuity, which was associated with the loss of structural integrity (e.g., under radial pressure and fatigue) of bioresorbable scaffolds during degradation.

Experimental studies of mechanical performance of stents, including in vitro and in vivo measurements, are currently ongoing in our research group, which will be utilized for model validation in future work. Also, in this work, the pulsatile loading was applied to both stent and plaque-artery as described in Section 2.4, and the fatigue simulations considered the full interaction between the stent and the plaque-artery. Therefore, the pulsatile stresses obtained for the stent included the effects of plaque-artery under fatigue deformation.

\section{Conclusions}

In this paper, the full process of stent deployment in diseased artery has been simulated for four bioresorbable polymeric stents, i.e., Absorb, Elixir, Igaki-Tamai and RevaMedical stents. Furthermore, fatigue deformation of implanted Elixir stent was simulated under cyclic systolic-diastolic blood pressure loading. The maximum von Mises stress and stress amplitude were found at the crests of stent U-bends, indicating a risk of fatigue failure. The Goodman's method was used to carry out fatigue life prediction, and the results 
suggested potential fatigue failure at the U-bend regions of polymer stent. However, the fatigue assessment has some limitations due to the lack of testing data for PLLA, and therefore further work is required in terms of material characterization and fatigue testing.

\section{Acknowledgements}

LG Zhao acknowledge the support from the British Heart Foundation (Grant number: FS/15/21/31424; Title: Towards controlling the mechanical performance of polymeric bioresorbable vascular scaffold during biodegradation) and the Royal Society of UK (Grant number: IE160066; Title: Evaluating the Performance of Additively Manufactured Endovascular Scaffolds)

\section{Conflict of Interest Statement}

Author TY Qiu, Author LG Zhao and Author M Song declare that they have no conflicts of interest to this work.

\section{Human and Animal Rights and Informed Consent}

This article does not contain any studies with human participants or animals performed by any of the authors.

\section{References}

1. Testa, L., Latib, A., Montone, R.A., Colombo, A., Bedogni, F. Coronary 
Bioresorbable Vascular Scaffold Use in the Treatment of Coronary Artery Disease. Cir. Cardiovasc. Inte. 9(7): e3978, 2016.

2. Pauck, R.G., Reddy, B.D. Computational analysis of the radial mechanical performance of PLLA coronary artery stents. Med. Eng. Phys. 37(1): 7-12, 2015.

3. Debusschere, N., Segers, P., Dubruel, P., Verhegghe, B., De Beule, M. A finite element strategy to investigate the free expansion behaviour of a biodegradable polymeric stent. J. Biomech. 48(10): 2012-2018, 2015.

4. Bobel, A. C., Petisco, S., Sarasua, J. R., Wang, W., \& Mchugh, P. E. Computational bench testing to evaluate the short-term mechanical performance of a polymeric stent. Cardiovasc. Eng. Techn. 6(4): 519-532, 2015.

5. Bobel, A. C., \& Mchugh, P. E. Computational analysis of the utilisation of the shape memory effect and balloon expansion in fully polymeric stent deployment. Cardiovasc. Eng. Techn. 9(1): 1-13, 2017.

6. Schiavone, A., Qiu, T., Zhao, L.G. Crimping and deployment of metallic and polymeric stents-finite element modelling. Vessel Plus. 1(1): 12-21, 2017.

7. Gao, R., Yang, Y., Han, Y., Huo, Y., Chen, J., Yu, B. Su, X., Li, L., Kuo, H.C., Ying, S.W., Cheong, W.F., Zhang, Y.L., Su, X.L., Xu, B., Popma, J.J, Stone, G.W. Bioresorbable vascular scaffolds versus metallic stents in patients with coronary artery disease: Absorb China trial. J. Am. Coll. Cardiol. 66(21):2298-2309, 2015.

8. Kimura, T., Kozuma, K., Tanabe, K., Nakamura, S., Yamane, M., Muramatsu, T. Saito, S., Yajima, J., Hagiwara, N., Mitsudo, K., Popma, J.J., Serruys, P.W., Ying, S.H., Cao, S., Staehr, P., Cheong W.F., Kusano, H., Stone, G.W. A randomized trial evaluating 
everolimus-eluting absorb bioresorbable scaffolds vs. everolimus-eluting metallic stents in patients with coronary artery disease: Absorb Japan. Eur. Heart J. 36(47): 3332-3342, 2015.

9. Xu, B., Yang, Y., Han, Y., Huo, Y., Wang, L., Qi, X., Li, J., Chen, Y., Kuo, H., Ying, S., Cheong, W., Zhang, Y., Su, X., Popma, J., Gao, R., Stone, G.W. Comparison of everolimus-eluting bioresorbable vascular scaffolds and metallic stents: three-year clinical outcomes from the ABSORB China randomised trial. Eurointervention. 14(5): 554-561, 2018.

10. Kereiakes, D., Ellis, S., Stone G. TCT-61 Clinical outcomes following complete bioresorption of the Absorb everolimus-eluting bioresorbable scaffold: Four-year results from the ABSORB III trial. J. Am. Coll. Cardiol. 72(13), B27, 2018.

11. Gao, R. TCT-310 Four-Year Clinical Outcomes from Randomized Comparison of Everolimus-eluting Bioresorbable Vascular Scaffolds Versus Everolimus-eluting Metallic Stents in Patients with Coronary Artery Disease From ABSORB China Trial. J. Am. Coll. Cardiol. 72 (13), B128, 2018.

12. Yamaji, K., Ueki, Y., Souteyrand, G., Daemen, J., Wiebe, J., Nef, H., Adriaenssens, T., Loh, J.P., Lattuca, B., Wykrzykowska, J.J., Gomez-Lara, J., Timmers, L., Motreff, P., Hoppmann, P., Abdel-Wahab, M., Byrne, R.A., Meincke, F., Boeder, N., Honton, B., O'Sullivan, C.J., Ielasi, A., Delarche, N., Christ, G., Lee, J.K.T., Lee, M., Amabile, N., Karagiannis, A., Windecker, S., Räber, L. Mechanisms of Very Late Bioresorbable Scaffold Thrombosis: The INVEST Registry. J. Am. Coll. Cardiol. 70(19): 2330-2344, 2017. 
13. Lee, S.H., Park, J.S., Shin, D.G., Kim, Y.J., Hong, G.R., Kim, W., Shim, B.S. Frequency of stent fracture as a cause of coronary restenosis after sirolimus-eluting stent implantation. Am. J. Cardiol. 100(4): 627-630, 2007.

14. Shaikh, F., Maddikunta, R., Djelmami-Hani, M., Solis, J., Allaqaband, S., Bajwa, T. Stent fracture, an incidental finding or a significant marker of clinical in-stent restenosis? Catheter. Cardio. Inte. 71(5): 614-618, 2008.

15. Nakazawa, G., Finn, A.V., Vorpahl, M., Ladich, E., Kutys, R., Balazs, I., Kolodgie, F.D., Virmani, R. Incidence and predictors of drug-eluting stent fracture in human coronary artery: a pathologic analysis. J. Am. Coll. Cardiol. 54(21): 1924-1931, 2009.

16. Bandar, A.M., Rosaire, M., Stephen, Y. Coronary stents fracture: an engineering approach (review). Mater. Sci. Applic. 4(10): 606-621, 2013.

17. Ang, H.Y., Bulluck, H., Wong, P., Venkatraman, S.S., Huang, Y. and Foin, N. Bioresorbable stents: Current and upcoming bioresorbable technologies. Int. J. Cardiol. 228: 931-939, 2016.

18. Gajjar, C.R., King, M.W. Degradation Process. In: Resorbable Fiber-Forming Polymers for Biotextile Applications. Springer Briefs in Materials. 7-10, 2014.

19. Li, J., Luo, Q., Xie, Z., Li, Y., Zeng, Y. Fatigue life analysis and experimental verification of coronary stent. Heart and vessels. 25(4): 333-337, 2010.

20. Azaouzi, M., Makradi, A., Belouettar, S. Fatigue life prediction of cardiovascular stent using finite element method. Comput. Method. Biomech. 15(1): 93-95, 2012.

21. Dordoni, E., Petrini, L., Wu, W., Migliavacca, F., Dubini, G., Pennati, G. Computational modeling to predict fatigue behavior of NiTi stents: What do we 
need? J. Funct. Biomater. 6(2): 299-317, 2015.

22. Holzapfel, G.A., Sommer, G., Gasser, C.T., Regitnig, P. Determination of layer-specific mechanical properties of human coronary arteries with nonatherosclerotic intimal thickening and related constitutive modeling. Am. J. Physiol-Heart C. 289(5): H2048-H2058, 2005.

23. Schiavone, A., Zhao, L.G. Abdel-Wahab A.A. Effects of material, coating, design and plaque composition on stent deployment inside a stenotic artery - Finite element simulation. Mater. Sci. Eng C. 42:479-488, 2014.

24. Schiavone, A., Abunassar, C., Hossainy, S., Zhao, L.G. Computational analysis of mechanical stress-strain interaction of a bioresorbable scaffold with blood vessel. J. Biomech. 49(13):2677-2683, 2016.

25. Holzapfel, G.A., Gasser, T.C., Ogden, R.W. A new constitutive framework for arterial wall mechanics and a comparative study of material models. J. Elasticity. 61: 1-48, 2000.

26. Gasser, T.C., Ogden, R.W., Holzapfel, G.A. Hyperelastic modelling of arterial layers with distributed collagen fibre orientations. J. R. Soc. Interface. 3(6): 15-35, 2006.

27. Holzapfel, G.A., Ogden, R.W. On the tension-compression switch in soft fibrous solids. Eur. J. Mech. A-Solids. 49(49): 561-569, 2015.

28. Li, K.W., Ogden, R.W., Holzapfel, G.A. Computational method for excluding fibers under compression in modeling soft fibrous solids. Eur. J. Mech. A-Solids. 57: 178-193, 2016.

29. Li, K.W., Ogden, R.W., Holzapfel, G.A. A discrete fibre dispersion method for 
excluding fibres under compression in the modelling of fibrous tissues. J. R. Soc. Interface. 15(138): 20170766, 2018.

30. Ogden, R.W. Large deformation isotropic elasticity-on the correlation of theory and experiment for incompressible rubberlike solids. P. Roy. Soc. Lond. A. Mat. 326(1567): 565-584, 1972.

31. Loree, H.M., Grodzinsky, A.J., Park, S.Y., Gibson, L.J., Lee, R.T. Static circumferential tangential modulus of human atherosclerotic tissue. J. Biomech. 27(2): 195-204, 1994.

32. Schiavone, A., Zhao, L.G. A computational study of stent performance by considering vessel anisotropy and residual stresses. Mater. Sci. Eng. C 62: 307-316, 2016.

33. Pierce, D.M., Fastl, T.E., Rodriguez-Vila, B., Verbrugghe, P., Fourneau, I., Maleux, G., Herijgers, P., Enrique, J., Holzapfel, G.A. A method for incorporating three-dimensional residual stretches/stresses into patient-specific finite element simulations of arteries. J. Mech. Behav. Biomed. Mater. 47: 147-164, 2015.

34. Weisbecker, H., Pierce, D.M., Holzapfel, G.A. A generalized prestressing algorithm for finite element simulations of preloaded geometries with application to the aorta. Int. J. Numer. Methods Biomed. Eng. 30: 857-872, 2014.

35. Gee, M.W., Förste,r C.H., Wall, W.A. A computational strategy for prestressing patient specific biomechanical problems under finite deformation. Int. J. Numer. Methods Biomed. Eng. 26: 52-72, 2010.

36. Vasava, P., Jalali, P., Dabagh, M., Kolari, P. J. Finite element modelling of pulsatile blood flow in idealized model of human aortic arch: study of hypotension and 
hypertension. Comput. Math. Method. M. 2012(1): ID861837, 2012.

37. Migliavacca, F., Petrini, L., Montanari, V., Quagliana, I., Auricchio, F. and Dubini, G. A predictive study of the mechanical behaviour of coronary stents by computer modelling. Med. Eng. Phys. 27(1): 13-18, 2005.

38. Averett, R.D. Experimental aspects and mechanical modeling paradigms for the prediction of degradation and failure in nanocomposite materials subjected to fatigue loading conditions. Dissertations \& Thesis-Gradworks. 2008.

39. Osswald, T.A. Understanding polymer processing: processes and governing equations. Understanding Polymer Processing, 2015.

40. Timmins, L.H., Meyer, C.A., Moreno, M.R., Moore, Jr, J.E. Mechanical modeling of stents deployed in tapered arteries, Ann. Biomed. Eng. 36(12): 2042-2050, 2008.

41. Bedoya J., Meyer C.A., Timmins L.H., Moreno M.R., Moore J.E. Effects of stent design parameters on normal artery wall mechanics, J. Biomech. Eng. 128(5): 757-765, 2006.

42. Dreher, M.L., Nagaraja, S., Batchelor, B. Effects of fatigue on the chemical and mechanical degradation of model stent sub-units. J. Mech. Behav. Biomed. Mater. 59: 139-145, 2016.

43. Yamaji, K., Ueki, Y., Souteyrand, G., Daemen, J., Wiebe, J., Nef, H., Adriaenssens, T., Loh, J.P., Lattuca, B., Wykrzykowska, J.J., Josep, J., Timmers, L., Motreff, P., Hoppmann, P., Abdel-Wahab, M., Byrne, R.A., Meincke, F., Boeder, N., Honton, B., O’Sullivan, C.J., Ielasi, A., Delarche, N., Christ, G., Lee, J.K.T., Lee, M., Amabile, N., Karagiannis, A., Windecker, S., Räber, L. Mechanisms of very late bioresorbable 
scaffold thrombosis - The INVEST registry. J. Am. Coll. Cardiol. 70: 2331-2344, 2017. 